\title{
EFFECT OF NOBLE METALS ON THE PROPERTIES OF NANOCOMPOSITES BASED ON SILICON STRUCTURES AND TITANIUM DIOXIDE, SYNTHESIZED FOR SOLAR COLLECTORS
}

\author{
Prof. Dr-Ing. Stefan Kirilov Kartunov
}

\begin{abstract}
This article analyzes the developments on the subject and draws conclusions for the study $1722 / \mathrm{M}-2017$. Most metals are highly chemically reactive, especially at nanoscale, without having properties that can be easily used with $\mathrm{TiO}_{2}$ composites. As such, most of the metals below will be considered metal oxides of precious metals. In addition, the most common oxide $\mathrm{TiO}_{2}$ will be discussed, as other oxides are probably unstable and thus do not form stable composites.
\end{abstract}

Keywords: nanocomposites , silicon structures, titanium dioxide

\section{INTRODUCTION}

A detailed consideration of all precious metals is given in study 1722 / M-2017 at the UZNIT of Technical University-Gabrovo and [1]. Only palladium, platinum, silver and gold are considered here.

\section{EXPOSITION}

The development of $\mathrm{Pd} / \mathrm{TiO}_{2}$-based palladium composites on visible light radiation was studied by Mohapatra. $\mathrm{TiO}_{2}$ nanoparticles were synthesized by $\mathrm{Ti}$ foil anodization followed by $\mathrm{PdCl}_{2}$ functionalization and subsequent $\mathrm{H}_{2} / \mathrm{Ar}$ calcining to crystallize $\mathrm{TiO}_{2}$ and converting the $\mathrm{Pd}$ salt to pure $\mathrm{Pd}$. The synthesized composite with optimized 1.25 wt $\%$ Pd showed significant photocatalytic improvement compared to naked $\mathrm{TiO}_{2}$ nanotubes. A nitrogen-dosed $\mathrm{Pd} / \mathrm{TiO}_{2}$-active to the visible light composite is also prepared. Prepared $\mathrm{TiO}_{2}$ nanotube matrices through a three-stage anodization of Ti foil, followed by calcination and hydrothermal reduction of $\mathrm{Pd}$ nanoparticles on the crystal $\mathrm{TiO}_{2}$ nanotubes in the presence of polyvinylpyrrolidone (PVP) and $\mathrm{Na} \mathrm{I}$ allow for controlling the PVPconcentration and the hydrothermal reaction time. Figures $1 \mathrm{a}$ and $1 \mathrm{~b}$ show a Scanning electron microscope (SEM)-image of a preconditioned nanotube matrix, and Figures1c and $1 \mathrm{~d}$ show the mass after hydrothermal deposition of $\mathrm{Pd}$. Figure 1 shows a Tunnel electron microscope (TEM)-image of the nanotube with clearly placed Pd-nanoparticles. No such silicon matrix composites are known.

Photocatalytic production of $\mathrm{Pt} / \mathrm{TiO}_{2}$ composites consistently shows increasing growth with the advancement of nanoscale synthesis and controllable/tunable properties of nanomaterials. These composites allow optimi-

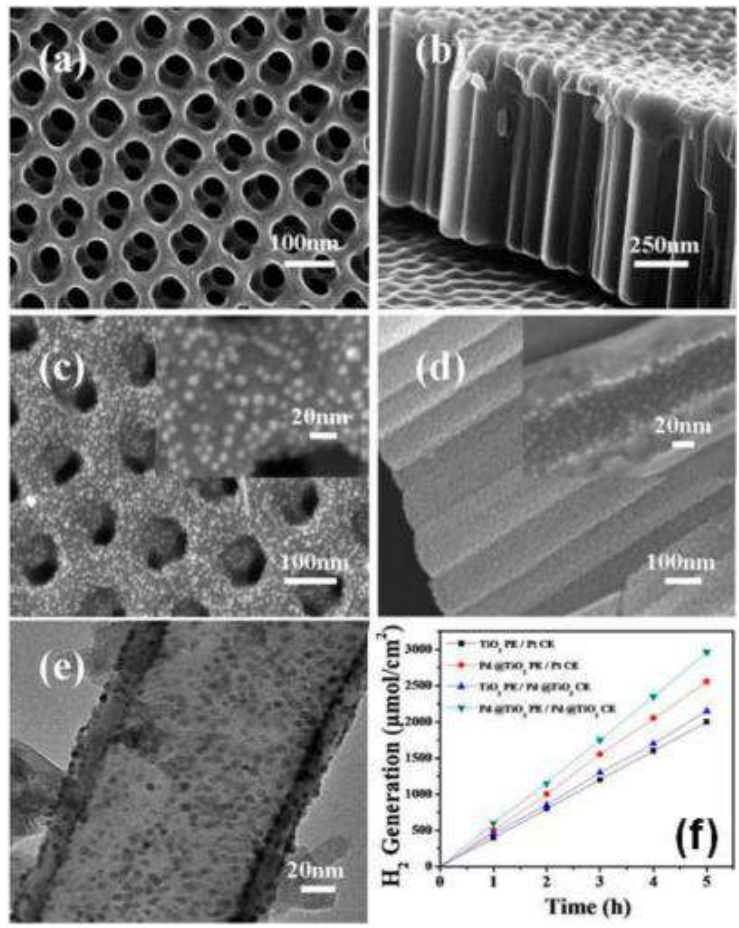

Figure 1. (a) and (b) SEM-images in cross-section of nanotubes $\mathrm{TiO}_{2}$ (TNTAs) obtained from electrochemical anodization. SEM-images of Pd composites deposited on TNTAs: (c) a top view of small and large magnifications; (d) a cross-sectional view (a large magnification of a broken tube is shown in the insert). (d) TEM-image of $\mathrm{TiO}_{2}$ nanotubes with deposited $\mathrm{Pd}$ composites showing that they are uniformly dispersed on nanotubes. f) A graph of the amount of hydrogen generated by $\mathrm{TiO}_{2}$ nanotubes and Pd/TNTA nanocomposites such as photon and Pt foil and Pd/TNTA nanocomposites as cathodes. $\mathrm{Pd} \%=2.15 \%$ wt. PE and CE respectively indicate photo anode and cathode electrodes

zation of parameters such as morphology, crystalline phase, crystallinity, porosity and surface area, each of which can alter the photoactivity of the composition. Improving photocatalytic activity with the introduction of $\mathrm{Pt}$ is typically attributed to the formation of a Schottky barrier at the metal- $\mathrm{TiO}_{2}$ interface. This happens because the work function of $\mathrm{Pt}$ $(\sim 5,36-5,63 \mathrm{eV})$ is greater than that of $\mathrm{TiO}_{2}(\sim$ 
4,6-4,7 eV), so that electrons are transferred at $\mathrm{Pt}$ and holes Localized in $\mathrm{TiO}_{2}$ media to improve photocatalytic efficiency. In order to improve the $\mathrm{Pt} / \mathrm{TiO}_{2}$ composites, steps have been taken to optimize the interaction between $\mathrm{Pt}$ and $\mathrm{TiO}_{2}$ from Kandiel, effectively effecting the surface area and crystal structure of $\mathrm{TiO}_{2}$ in the resulting $\mathrm{Pt} / \mathrm{TiO}_{2}$ composite and demonstrating that although the large Area is useful, increasing crystallinity is preferential. Increasing photocatalytic activity is due to the reduction of site defects that act as charge recombination centers when crystallinity increases.

Due to their low price compared to other precious metals, intensive localized surface plasma resonance (LSPR) and easy shape control, silver nanomaterials are used in $\mathrm{TiO}_{2}$ composites to a considerable extent. Silver is widely used with $\mathrm{TiO}_{2}$ to produce composites to decompose photocatalytic organic molecules, DSS-composites, photoactive bactericides, photochromic materials and other applications. Although silver can not recombine $\mathrm{H}+$ atoms for hydrogen production, on the basis of its slightly larger function, $\sim 4.7$ and $4.6 \mathrm{eV}$ for $\mathrm{Ag}$ and $\mathrm{TiO}_{2}$, respectively still has the ability to attract photogenerated electrons of $\mathrm{TiO}_{2}$ and thus improve the separation of the charge. Many reports show improved UV-photocatalytic degradation of organic pollutants from $\mathrm{Ag} / \mathrm{TiO}_{2}$ composites compared to pure $\mathrm{TiO}_{2}$. Although the precise nature of LSPR on improved photocatalytic activity has not been fully investigated, it is clear that it improves the photocatalytic activity of $\mathrm{TiO}_{2}$ and the generation of photoelectrochemical currents. In the Awazu study, it can be seen that direct contact between $\mathrm{Ag}$ and $\mathrm{TiO}_{2}$ is not necessary for photocatalytic amplification, which suggests that the reason is the increase of the Ag LSPR electromagnetic field.

In this study, silver nanoparticles are embedded in $\mathrm{SiO}_{2}$ layers of varying thickness, followed by a $\mathrm{TiO}_{2}$ layer, which is of particular interest to the topic. It is shown that when the $\mathrm{SiO} 2$ layer is thinner, photocatalytic degradation increases even without contact with $\mathrm{TiO}_{2}$. The system consists of $\mathrm{Ag}$ nanoparticles, coated with different $\mathrm{TiO}_{2}$ thickening particles. As shown in Figure 2b, $\mathrm{TiO}_{2}$ 's finest coatings give the greatest improvement in IPCEs, due to the larger electromagnetic field attributed to silver nanoparticles. This in turn leads to greater cellular efficacy as shown in Figure 2c.
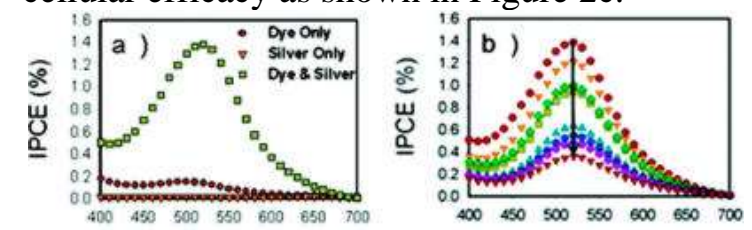

Wavelength $(\mathrm{nm})$

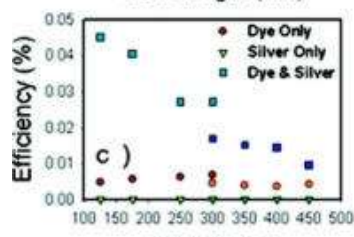

$\mathrm{TiO}_{2}$ Cycles

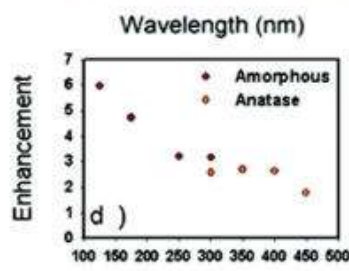

$\mathrm{TiO}_{2}$ Cycles

Figure 2. IPCE and general trends in cells. (a) IPCE for cells with 125 cycles of amorphous $\mathrm{TiO}_{2}$. (b) IPCE for silver-plated cells. The indicator shows an increase in $\mathrm{TiO}_{2}$ thickness. The first four spectra and the two spectra correspond to amorphous and anode $\mathrm{TiO}_{2}$. (c) Cell efficiency. Dark blue, orange and green symbols match the anatomy samples. Light blue, red, and yellow symbols correspond to amorphous samples. (d) Calculated plasma increase factor as a function of $\mathrm{TiO}_{2}$ thickness

In order to better investigate the effects of the metal- $\mathrm{TiO}_{2}$ interaction in the $\mathrm{Ag} / \mathrm{TiO}_{2}$ composite, core $\mathrm{Ag} / \mathrm{TiO}_{2}$ structures were synthesized. The original core composites were manufactured by Liz-Marzan and others, but the $\mathrm{Ag} / \mathrm{TiO}_{2}$ composite nuclear coatings specifically made for interaction studies were first synthesized and tested by Hirakawa and Kamat. Reversible charge and dilution of the $\mathrm{Ag}$ core of photocurrent electrons from the $\mathrm{TiO}_{2}$ shell is observed, and when the composite is irradiated, the electrons are moved to the $\mathrm{Ag}$ core because the holes generated in $\mathrm{TiO}_{2}$ are extracted from ethanol. Details can be seen in study 1722 / M-2017.

Compared to platinum and silver, gold has advantages over each of them. Like silver, gold has an adjustable LSPR, that can be used to improve photocatalytic activity, but also has a stronger chemical stability similar to platinum. In addition, gold has a high duty function ( 5.1-5.3 eV). Based on this, the $\mathrm{Au} / \mathrm{TiO}_{2}$ composites are used for many of the same applications as $\mathrm{Pt}$ and $\mathrm{Ag}$, with some improvements depending on the case. Typically, $\mathrm{Au} / \mathrm{TiO}_{2}$ composites have a better $\mathrm{Ag} / \mathrm{TiO}_{2}$ photoactivity because the higher gold function compared to silver allows better separation of the $\mathrm{TiO}_{2}$ charge. In addition to applications for degradation of organic 
molecules and hydrogen production, the $\mathrm{Au} / \mathrm{TiO}_{2}$ composites are heavily used for $\mathrm{CO}$ oxidation, which is of importance to the environment due to its release from combustion of fuels in internal combustion engines. It is known that $\mathrm{Au} / \mathrm{TiO}_{2}$ composites effectively convert $\mathrm{CO}$ to $\mathrm{CO}_{2}$, even at temperatures below $0^{\circ} \mathrm{C}$. Various factors may influence the activity of $\mathrm{CO} / \mathrm{CO}_{2}$ oxidants, in particular the particle size of $\mathrm{Ag}$, but also the $\mathrm{TiO}_{2}$ crystallinity and the method of composing the composite. The deactivation of the composite, due to Au particle sintering, is particularly important because in practical applications such as catalytic converters the composite would be subjected to high temperatures $\left(>750^{\circ} \mathrm{C}\right)$. In order to prevent this deactivation, Lee's study uses an $\mathrm{Au} / \mathrm{TiO}_{2}$ catalyst of methyl-orange that can effectively prevent the sintering of $\mathrm{Au}$ nanoparticles by placing a physical $\mathrm{TiO}_{2}$ barrier.

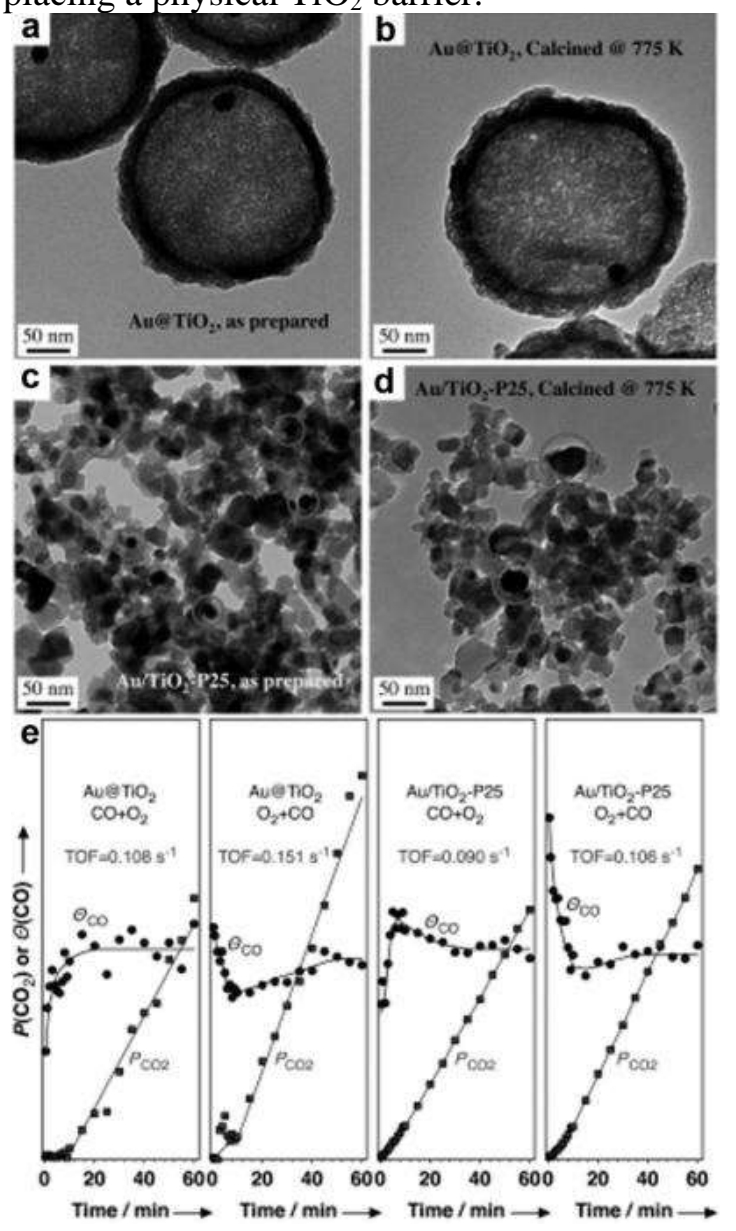

Figure 3. (a) TEM-image of the prepared $\mathrm{Au} / \mathrm{TiO} 2$ structure. (b) TEM-image of the $\mathrm{Au} / \mathrm{TiO}_{2}$ calcite structure. c) TEM-image of the prepared Au/P25 sample. d) TEM-image of the Au /P25 sample after calcification. e) Time dependence of carbon oxide coating on gold and partial pressure of carbon dioxide during oxidation of $\mathrm{CO}$ at room temperature of $\mathrm{CO}$ with gold/titanium base catalysts. The two left panels correspond to the $\mathrm{Au} / \mathrm{TiO}_{2}$ catalyst and the right panel to the reference $\mathrm{Au} / \mathrm{TiO}_{2}-\mathrm{P} 25$ sample. First and third panels are obtained by first introducing $\mathrm{CO}$ at a pressure of 200Torr into the cell; In the second and fourth panel the sequence is reversible. $\mathrm{CO}$ coating of $\mathrm{Au}$ in gas phase $\mathrm{CO}_{2}$ is calculated from the integrated intensities of DRIFT signals in the regions 2090-2145 and 2300-2400 $\mathrm{cm}^{-1}$ respectively.

In this study is suggested an $\mathrm{Au} / \mathrm{TiO}_{2}$ composite consisting of a nanoparticle of gold $(\sim 15 \mathrm{~nm})$ in porous $\mathrm{TiO}_{2}$ and is also available. The composite is made by applying the nanoparticles $\mathrm{Au}$ first with a $\mathrm{SiO}_{2}$ layer and then coating the $\mathrm{TiO}_{2}$ layer composite. The $\mathrm{SiO}_{2}$ can then be removed from the composite by dissolution with $\mathrm{NaOH}$ as shown in Figure 3a. The composite can then be calcined and crystallized $\mathrm{TiO}_{2}$ without alteration of the $\mathrm{Au}$ nanoparticles, as shown in Figure 3b. This result is compared with the $\mathrm{Au} / \mathrm{TiO}_{2}-\mathrm{P} 25$ composite calcification, where it is clear that $\mathrm{Au}$ nanoparticles are synthesized significantly (Figure 3d). All this and the applicationis the subject of further research.

\section{CONCLUSIONS}

1.No precious metal $(\mathrm{Pd})$ composites of silicon matrix and metal oxides- $\mathrm{TiO}_{2}$ are known.

2.In this study, silver nanoparticles are proposed to be embedded in $\mathrm{SiO}_{2}$-layers of varying thickness, followed by a $\mathrm{TiO}_{2}$ layer. It is shown that when the $\mathrm{SiO}_{2}$ layer is thinner, photocatalytic degradation increases even without contact with $\mathrm{TiO}_{2}$.

3.An $\mathrm{Au} / \mathrm{TiO}_{2}$ composite, consisting of a nanoparticle of gold $(\sim 15 \mathrm{~nm})$ in porous $\mathrm{TiO}_{2}$ is synthesized. The composite is made by applying the nanoparticles $\mathrm{Au}$ first with a $\mathrm{SiO}_{2}$ layer and then coating the $\mathrm{TiO}_{2}$ layer composite. The $\mathrm{SiO}_{2}$ can then be removed from the composite by dissolution with $\mathrm{NaOH}$. The composite can then be calcined and crystallized $\mathrm{TiO}_{2}$ without alteration in the $\mathrm{Au}$ nanoparticles. All this is the subject of further research on solar collectors.

\section{References}

[1]. Къртунов С.,Технологични основи в мехатрониката, микро- и наносистемната техника, (учебник-монография), Габрово, УИ „В.Априлов”, 2012 година, ISBN 978954-683-482-9 9 (in bulgarian)

\section{About the author}

Prof. Dr-Ing. Stefan Kartunov, TU Hadji Dimitar Str. 4, Department MU, Mechanical Engineering, Tel.++35966827365, Lab. Micro- and Nanotechnologies 